flares occuring six months before/after their introduction, using medical files and phone inquiry.

Results: Twenty-three patients were included in this study. Data about RA treatments and SCD flares could be collected for 15 patients. Middle age at RA diagnostic was 32.9 years-old, sexe ratio was $4.75 \mathrm{~F} / 1 \mathrm{M}$. $74 \%$ of the patients were RF positive, $65 \%$ were ACPA positive. $74 \%$ of the patients had articular damages. Among them, $100 \%$ had severe carpite which appears to be the major radiological expression of RA in SCD patients, occuring sometimes without finger bone erosion. $100 \%$ received at least one specific drug for RA, 35\% a biotherapy. There was no significant difference in the number of crisis before and after methotrexate introduction $(p=1)$ or anti TNF alpha drugs $(p=0.35$ IC95\% [-1.26;0.51]. Methotrexate had to be stopped for 3 patients because of acute chest syndrome, which did not occur with anti TNF. No infection was noticed.

Conclusions: In conclusion, in SCD, RA occurs sooner in life course and to be more severe with a particular pattern: carpite and tarsite without finger bone erosion. The use of biotherapy appears to be safe, with a close monitoring

Disclosure of Interest: None declared

DOI: 10.1136/annrheumdis-2018-eular.2651

\section{AB0364 REMARKABLE INTERNATIONAL VARIABILITY IN REASONS FOR NON-PARTICIPATION IN THE GLORIA TRIAL}

L. Hartman ${ }^{1}$, R. Bos ${ }^{2}$, F. Buttgereit ${ }^{3}$, M. Güler-Yuksel ${ }^{4}$, R. Ionescu ${ }^{5}$, M. Kok ${ }^{4}$ W. Lems ${ }^{1}$, M. Micaelo ${ }^{6}$, D. Opris-Belinski ${ }^{5}$, A. Pusztai ${ }^{7}$, E. Santos ${ }^{8}$, J. da Silva ${ }^{8}$, Z. Szekanecz ${ }^{7}$, K. Zeiner ${ }^{3}$, D. Zhang ${ }^{2}$, M. Boers ${ }^{1,9}$. ${ }^{1}$ Amsterdam Rheumatology and Immunology Center ARC, Amsterdam; ${ }^{2}$ Rheumatology, Medical Center Leeuwarden, Leeuwarden, Netherlands; ${ }^{3}$ Department of Rheumatology and Clinical Immunology, Charité - University Medicine Berlin, Berlin, Germany; ${ }^{4}$ Department of Rheumatology and Clinical Immunology, Maasstad Hospital, Rotterdam, Netherlands; ${ }^{5}$ Department of Internal Medicine and Rheumatology, 'Sf. Maria" Hospital, University of Medicine and Pharmacy "Carol Davila", Bucharest, Romania; ${ }^{6}$ Instituto Português de Reumatologia, Lisbon, Portugal; ${ }^{7}$ Department of Rheumatology, University of Debrecen Faculty of Medicine, Debrecen, Hungary; ${ }^{8}$ Reumatologia, Faculdade de Medicina e Hospitais da Universidade de Coimbra, Coimbra, Portugal; ${ }^{9}$ Department of Epidemiology and Biostatistics, VU University Medical Center, Amsterdam, Netherlands

Background: GLORIA is an ongoing large pragmatic trial that examines harm, benefit and costs of low-dose glucocorticoids added to the standard treatment of RA patients of 65 years or older. The eligibility criteria are non-restrictive: RA, age $\geq 65$ years, disease activity score (DAS28) of $\geq 2.6$, and no current glucocorticoid treatment. Patients with comorbidity are expressly included, and the impact of trial procedures on normal care is minimal. Nevertheless, inclusion proves to be challenging. We have prospectively sampled all the reasons for ineligibility across a number of centres in different countries participating in the GLORIA trial.

Methods: Rheumatologists from 8 centres in Germany, Hungary, The Netherlands, Portugal and Romania screened the patient list of at least two full clinic days. For each patient, the eligibility and all possible reasons of exclusion were recorded.

Abstract AB0364 - Table 1. Percentage of patients ineligible for the GLORIA trial, per reason (patients can have more than one reason)

\begin{tabular}{|c|c|c|c|c|c|c|}
\hline \multirow[b]{2}{*}{ Center } & \multicolumn{6}{|c|}{ Percent ineligible for: } \\
\hline & $\mathrm{n}$ & Age & $\begin{array}{l}\text { Disease } \\
\text { Activity }\end{array}$ & $\begin{array}{c}\text { Current } \\
\text { GC }\end{array}$ & Temporary & Other \\
\hline Total & 370 & 58 & 58 & 28 & 5 & 11 \\
\hline \multicolumn{7}{|l|}{ The Netherlands } \\
\hline Amsterdam & 156 & 54 & 70 & 22 & 5 & 11 \\
\hline Rotterdam & 43 & 63 & 58 & 12 & 2 & 9 \\
\hline Leeuwarden & 46 & 51 & 70 & 11 & 4 & 19 \\
\hline Germany, Berlin & 23 & 52 & 52 & 65 & 0 & 17 \\
\hline \multicolumn{7}{|l|}{ Portugal } \\
\hline Coimbra & 21 & 58 & 21 & 8 & 4 & 17 \\
\hline Lisbon & 10 & 60 & 60 & 80 & 80 & 10 \\
\hline Hungary, Debrecen & 46 & 75 & 43 & 55 & 0 & 2 \\
\hline Romania, Bucharest & 18 & 56 & 22 & 44 & 0 & 6 \\
\hline
\end{tabular}

Results: In total, 385 patients were screened. Of these patients, 15 (4\%) were eligible to participate in the GLORIA trial. In Germany, Romania and Portugal (Lisbon) none of the screened patients proved eligible.
The most common reasons for ineligibility were inactive disease and age (both $58 \%$ ) (table 1). Current glucocorticoid use was reported in $28 \%, 5 \%$ had a temporary reason (i.e. recent switch of therapy or glucocorticoid use), and $51 \%$ had more than one reason for ineligibility. We found remarkable differences between the sites in the distribution of the main reasons for ineligibility (table 1).

Of the eligible patients, 1 was already participating, 3 were included after this screening, and 2 were currently considering participation; 9 declined participation (most common reasons: fear of glucocorticoids, not interested to participate, preference for GC injections or declining additional therapy).

Conclusions: In this prospective study, we found remarkable differences between countries in reasons for non-participation in our ongoing GLORIA trial. The willingness of eligible patients to participate was low in this elderly population despite the pragmatic design. Earlier studies also showed that it is challenging to include elderly patients in a clinical trial. ${ }^{12}$ Pre-screening of patients in potential sites can provide important information on the potential to recruit patients in a trial, but the actual willingness of patients to participate remains hard to predict.

\section{REFERENCES:}

[1] Calamia M, et al. I'd Do Anything for Research, But I Won't Do That: Interest in Pharmacological Interventions in Older Adults Enrolled in a Longitudinal Aging Study. PLoS One 2016;11:e0159664.

[2] Denson AC, et al. Participation of the elderly population in clinical trials: barriers and solutions. Cancer Control 2014;21:209-14

Acknowledgements: This project has received funding from the European Union's Horizon 2020 research and innovation programme under grant agreement No 634886 .

Disclosure of Interest: None declared

DOI: 10.1136/annrheumdis-2018-eular.2898

\section{AB0365 THE INSULIN RESISTANCE, METABOLIC SYNDROME AND TYPE 2 DIABETES MELLITUS DEVELOPMENT RISK ASSESSMENT IN RHEUMATOID ARTHRITIS PATIENTS}

L. Kondratyeva, T. Popkova. V.A. Nasonova Research Institute of Rheumatology, Moscow, Russian Federation

Background: The insulin resistance (IR) is the known risk factor of type 2 diabetes mellitus (DM) and potential cardiovascular complications. But it's not feasable in routine practice to calculate special indices to determine IR, as insulin levels monitoring is not a standard procedure in RA pts. Metabolic syndrome (MS) criteria and questionnaires designed to assess the risk of DM development can help to differentiate a subgroup of pts, requiring more accurate evaluation of their IR status.

Objectives: To determine how IR relates with MS and DM development risk assessment in RA patients.

Methods: A total of 46 RA pts (39 women, 7 men, 57 [39; 64] years old) without established DM were enrolled in the study, including 14 pts with IR and 32 pts without IR, matched by age and sex. IR was defined as Homeostasis Model Assessment of Insulin Resistance (HOMA-IR) index $>2,77$. National Cholesterol Education Program/Adult Treatment Panel III (NCEP/ATPIII) and International Diabetes Federation (IDF) criteria were used to confirm MS. The abdominal obesity was determined as waist circumference (WC) $>80 \mathrm{~cm}$ for women and $\geq 94 \mathrm{~cm}$ for men (by IDF), and WC $\geq 88 \mathrm{~cm}$ for women and $\geq 102 \mathrm{~cm}$ for men (by NCEP/ATPIII). If the total score of questionnaire Finnish Type 2 Diabetes Risk Assessment Form (FINDRISK) was $\geq 12$, the DM development risk was considered as moderate or high.

Results: The body mass index was higher in pts with IR than in those without IR $\left(28,5\left[24,8 ; 32,5 \mathrm{~kg} / \mathrm{m}^{2}\right.\right.$ vs $22,4\left[20,1 ; 25,4 \mathrm{~kg} / \mathrm{m}^{2}, \mathrm{p}<0,001\right)$. Abdominal obesity was documented in $100 \%$ pts with IR and in $41 \%$ pts without IR by IDF criteria $(p=0,002)$, in $64 \%$ and $22 \%$ pts, respectively, by NCEP/ATPIII criteria $(p=0,01)$. There were no differences in DAS28, CRP and ESR values and glucocorticoids users proportions. MS by IDF criteria was diagnosed in $57 \%$ pts with IR and $19 \%$ pts without IR $(\mathrm{p}=0,02)$, and MS prevalence by NCEP/ATP III criteria was similar in both groups ( $36 \%$ vs $16 \%$, respectively, $p=0,2)$. Higher rates of moderate and high risk for DM development were found in pts with IR compared to pts without IR ( $71,4 \%$ vs $31,2 \%, p=0,03)$.

Conclusions: The FINDRISK and IDF questionnaires, but not the NCEP/ATP III criteria of MS, can be helpful in selecting RA pts with potential IR. Abdominal obesity was the key factor indicative of IR in RA pts. On the other hand, IR may not be there even in the presence of several traditional DM risk factors. Therefore further clarification of potential contribution of RA-related risks is needed.

Disclosure of Interest: None declared

DOI: 10.1136/annrheumdis-2018-eular.3264 